Revista Geográfica Digital. IGUNNE. Facultad de Humanidades. UNNE. Año 13. № 26 . Julio

- Diciembre 2016. ISSN 1668-5180 Resistencia, Chaco

\title{
CARACTERÍSTICAS MORFOMÉTRICAS DE LAGUNAS DEL VALLE ALUVIAL DEL RÍO ALTO PARANÁ (TRAMO YACYRETÁ-CONFLUENCIA)
}

\section{MORPHOMETRIC CHARACTERISTICS OF LAGOONS IN THE ALLUVIAL VALLEY OF THE UPPER PARANÁ RIVER (STRETCH: YACYRETÁ-CONFLUENCE)}

Julio César Meza

Instituto de Investigaciones Geohistóricas (CONICET - UNNE)

julio 4152@hotmail.com

Prof. Félix Ignacio Contreras

Centro de Ecología Aplicada del Litoral (CONICET - UNNE)

Facultad de Ciencias Exactas y Naturales y Agrimensura (UNNE)

figcontreras@hotmail.com

\section{RESUMEN}

En el valle aluvial del río Paraná en su tramo comprendido entre la represa de Yacyretá y la confluencia con el río Paraguay se localizan ambientes lénticos que se ven condicionados por la dinámica hidrosedimentológica del río. Los cuerpos lagunares representan aquí un escenario útil para la identificación de procesos y factores relacionados con la actividad biológica. Por tal motivo, son fundamentales los estudios geomorfológicos, ya que condicionan los parámetros fisicoquímicos y biológicos de estos ambientes. La morfometría es una de las variables que afectan a estos parámetros, asimismo, permite identificar la dinámica de estos cuerpos en relación a los pulsos de inundación. En ese sentido, este trabajo aborda la distribución y caracterización morfométrica de lagunas del valle aluvial del río Alto Paraná entre la represa Yacyretá y su confluencia con el río Paraguay.

\section{PALABRAS CLAVES}

Lagunas, valle aluvial, morfometría.

\section{ABSTRACT}

In the alluvial valley of the Paraná River, in its section between the Yacyretá Dam and the confluence with the Paraguay River there are lentic environments constrained by the hydrosedimentological dynamic of the river. From the point of view of the Geomorphology, there are few studies concerning/about the bodies of water located there; however, there have been a lot of research that focus their attention from the biological perspective. The lagoon bodies represent here a useful scenario for the identification of processes and factors related to the biological activity. For this reason, the geomorphological studies are fundamental as they affect the physicochemical and biological parameters of these environments. Morphometry is one of the variables that affect these parameters; it also allows the identification of the dynamics of these bodies in relation to the pulses of flooding. In this sense, this paper deals with the distribution and morphometric characterization of lagoons in the alluvial valley of the Upper Paraná River between the Yacyretá Dam and its confluence with the Paraguay River.

\section{KEY WORDS}

Lagoons, alluvial valley, morphometry

Publicado en formato digital: Julio César Meza y Prof. Félix Ignacio Contreras. CARACTERÍSTICAS MORFOMÉTRICAS DE LAGUNAS DEL VALLE ALUVIAL DEL RÍO ALTO PARANÁ (TRAMO YACYRETÁCONFLUENCIA). Revista Geográfica Digital. IGUNNE. Facultad de Humanidades. UNNE. Año 13. № 26. Julio - Diciembre 2016. ISSN 1668-5180 Resistencia, Chaco.

En: http://hum.unne.edu.ar/revistas/geoweb/default.htm 
Revista Geográfica Digital. IGUNNE. Facultad de Humanidades. UNNE. Año 13. № 26. Julio

- Diciembre 2016. ISSN 1668-5180 Resistencia, Chaco

\section{INTRODUCCIÓN}

El tramo del río Paraná denominado Alto Paraná nace en Brasil, de la confluencia del río Grande y el río Paranaíba, y se extiende hasta su confluencia con el río Paraguay. Después de la represa de Yacyretá, situada entre las ciudades de Ituzaingó (Argentina) y Ayolas (Paraguay), enclavada en la zona conocida como los rápidos de Apipé, el río presenta una clara dirección hacia el oeste; sobre el territorio correntino es un río de valle aluvial que se abre en varios brazos que encierran grandes islas como las de Yacyretá y las de Ibicuy Talavera, Apipé Grande, Apipé Chico y otras menores. (Sarafian, 2006/2007).

El río Paraná presenta en su tramo superior un cauce angosto, con rápidos, islas y afloramientos de roca basáltica, accidentes estos derivados de los caracteres fisiográficos de la región que atraviesa (Drago, 1973:32).

En su primer tramo, el Alto Paraná es un río de meseta, de orillas con barrancas, que se distancian, cada vez más, unas de otras. El lecho es rocoso, sinuoso y desparejo, lo que produce gran cantidad de saltos, remolinos y correderas, como los de Urubú Punga y Guaira. En el segundo tramo corre encajonado $y$, por ambas márgenes, le llegan decenas de arroyos cortos pero caudalosos, debido a la abundancia de precipitaciones en la región. En el tramo correntino-paraguayo el río se transforma, pues disminuyen las barrancas, así como la pendiente y el desnivel de su lecho, y se ensancha, llegando a medir $3.000 \mathrm{~m}$. de margen a margen, y presentando numerosas islas de gran tamaño, que se interponen en su recorrido (Ríoparaná.org, 2011). (1)

Como señala Serra (s/f), el río hasta proximidades de Ituzaingó y hacia el este, escurre sobre rocas basálticas, resistentes, lo cual obliga a las aguas a moverse dentro de un cañón que si bien es ancho, posee paredes escarpadas que las encauzan. Es probable que el modelado del valle en ese sector se deba no sólo a la pura acción hidráulica, sino también a corrasión mecánica ejercida por los materiales acarreados o bien a crisis rexistásicas, con procesos de profundización y ensanchamiento. En el tramo oeste y norte- sur el lecho es de material suelto, arenoso, fácilmente removible.

A partir de Posadas, el canal simple y profundo del río Paraná encajonado por formaciones de basalto, se transforma en un canal entrelazado (Marchese et al. 2002, cit. por Poi y Galassi, 2014) o diseño de cauce múltiple, sembrado de bancos e islas de forma alargada en dirección este-oeste (Minottia, 2013 cit. por Valenzuela 2014), es decir, unos $300 \mathrm{Km}$. antes de pasar por la ciudad de Corrientes, se divide en varios brazos, separados entre sí por las mencionadas islas paraguayas y argentinas. Los pasos son de fondo rocoso y se asemejan a canales angostos y sinuosos, de poca profundidad, por los que el agua corre con gran velocidad, alcanzando en algunos puntos los $13 \mathrm{Km}$. por hora. (Ríoparaná.org, 2011). En este tramo del río se encuentran algunas grandes islas como la de Yacyretá que son fruto del afloramiento del basalto que las aguas de las grandes crecientes no llegan a cubrir.

A partir de la represa binacional Yacyretá, y hasta la ciudad de Corrientes el río posee una notable dirección hacia el oeste, y el cauce principal corre apoyado sobre la margen izquierda, es decir, sobre la ribera correntina del bloque mesopotámico. En consecuencia, el valle de inundación del rio presenta mayor desarrollo sobre su margen derecha, correspondiente a territorio paraguayo.

El borde costero correntino está constituido por un dique natural de origen sedimentario, cortado espaciadamente por arroyos, activos y antiguos, de los ríos que desaguan en el Paraná; con presencia de roca arenisca ferruginosa que aflora espaciadamente formando salientes que se adentran en el curso fluvial, que provocan una dinámica fluvial que produce el continuo socavamiento y depósito de sedimentos. Debido a esta dinámica, se genera un borde sinuoso e irregular, interrumpido por desembocaduras de arroyos, con entrantes y salientes, con sectores altos y bajos, donde se definen al menos tres sectores diferenciados en cuanto a sus condiciones naturales:

Publicado en formato digital: Julio César Meza y Prof. Félix Ignacio Contreras. CARACTERÍSTICAS MORFOMÉTRICAS DE LAGUNAS DEL VALLE ALUVIAL DEL RÍO ALTO PARANÁ (TRAMO YACYRETÁCONFLUENCIA). Revista Geográfica Digital. IGUNNE. Facultad de Humanidades. UNNE. Año 13. № 26. Julio - Diciembre 2016. ISSN 1668-5180 Resistencia, Chaco.

En: http://hum.unne.edu.ar/revistas/geoweb/default.htm 
bañados o zonas bajas, donde el río ingresa en las crecientes, cubiertos de vegetación; zonas de depósitos arenosos o playas, en general, continuo a las salientes rocosas (aguas abajo), y las zonas más altas del dique o albardón que forma barrancas (Valenzuela, 2014).

La planicie del río tiene escaso desarrollo en este sistema debido a que el curso del río corre encajonado con albardones abruptos y playas angostas. La margen izquierda es escarpada y solo está afectada por crecidas extraordinarias (Poi y Galassi, 2013: 209). Sin embargo, en los momentos de bajas y altas aguas en la cuenca, por las características señaladas, en este tramo la planicie no presenta gran extensión en este tramo, si lo comparamos con el Paraná medio cuyo valle de inundación comienza a ensancharse a partir de la ciudad de Corrientes con $10 \mathrm{~km}$ de ancho y $60 \mathrm{~km}$ en su desembocadura (Paira, 2003). El tramo actual, desde Ituzaingó a Confluencia, fue labrado sobre el antiguo trazado del actual río Yabebirí y por ello presenta características tan diferentes al tramo situado al sur de Confluencia (Popolizio, 2006).

Según Contreras y Paira (2015), dado el tamaño de la cuenca del río Paraná, es posible encontrar diversos humedales, tanto lóticos como lénticos, cuyos orígenes y dinámicas geomorfológicas actuantes difieren completamente, al margen de encontrarse dentro de una misma región y/o a pocos kilómetros de distancia.

Siguiendo a Poi y Galassi (2013) en este tramo pueden identificarse cuatro sectores funcionales: el cauce del rio Paraná, como se dijo con un diseño de cauce múltiple sembrado de bancos e islas de cauce alargadas. Presenta un fondo arenoso y limoso mayoritariamente, excepto el sector comprendido entre Ituzaingó e Itá-lbaté que presenta barrancas altas y lecho rocoso; los cuerpos lagunares de las islas y valle aluvial en general; los ambientes de bajos de las orillas, con playas, carrizales y pajonales que quedan cubiertos según el nivel del río, y las desembocaduras de cursos cortos y canalizaciones de arroceras.

El funcionamiento y estructura de los ríos con planicie de inundación, como el Paraná, están condicionados por las inundaciones periódicas (Casco, 2003: 1). Hoy se conoce que, en realidad, se trata de "pulsos de energía y materia" o "pulso hidrosedimentológico" (Neiff, 1990). En ríos como el Paraguay o el Paraná, las crecientes y las bajantes conforman dos fases complementarias del pulso: aguas altas o potamofase y aguas bajas o limnofase las cuales tienen una influencia notable en la estabilidad de los ecosistemas del macrosistema fluvial (Neiff, 1990; 1996; 1999).

Es por ello que las lagunas ubicadas en los valles aluviales, a diferencia de otros cuerpos de agua lénticos, presentan una dinámica geomorfológica mucho más activa relacionadas con los pulsos hidrosedimentológicos, presentando grandes variaciones en las características de sus aguas, ya sea antes, durante y posteriormente de manifestarse la potamofase. El principal ejemplo de ello es la renovación de las aguas de estas lagunas como se puede observar en la figura 1, donde se muestra la situación de varias lagunas de una isla del valle aluvial en aguas bajas y en aguas altas.

Los ambientes lénticos que se localizan en el valle aluvial del río Alto Paraná (Fig. 2) se ven condicionados por los pulsos de inundación que produce un intercambio lateral de agua, nutrientes y organismos entre el cauce principal de un río y los ambientes asociados al valle aluvial (Junk, 1989; Neiff, 1990), representando un escenario útil para la identificación de los factores y procesos que inciden en la actividad biológica.

Publicado en formato digital: Julio César Meza y Prof. Félix Ignacio Contreras. CARACTERÍSTICAS MORFOMÉTRICAS DE LAGUNAS DEL VALLE ALUVIAL DEL RÍO ALTO PARANÁ (TRAMO YACYRETÁCONFLUENCIA). Revista Geográfica Digital. IGUNNE. Facultad de Humanidades. UNNE. Año 13. № 26. Julio - Diciembre 2016. ISSN 1668-5180 Resistencia, Chaco.

En: http://hum.unne.edu.ar/revistas/geoweb/default.htm 

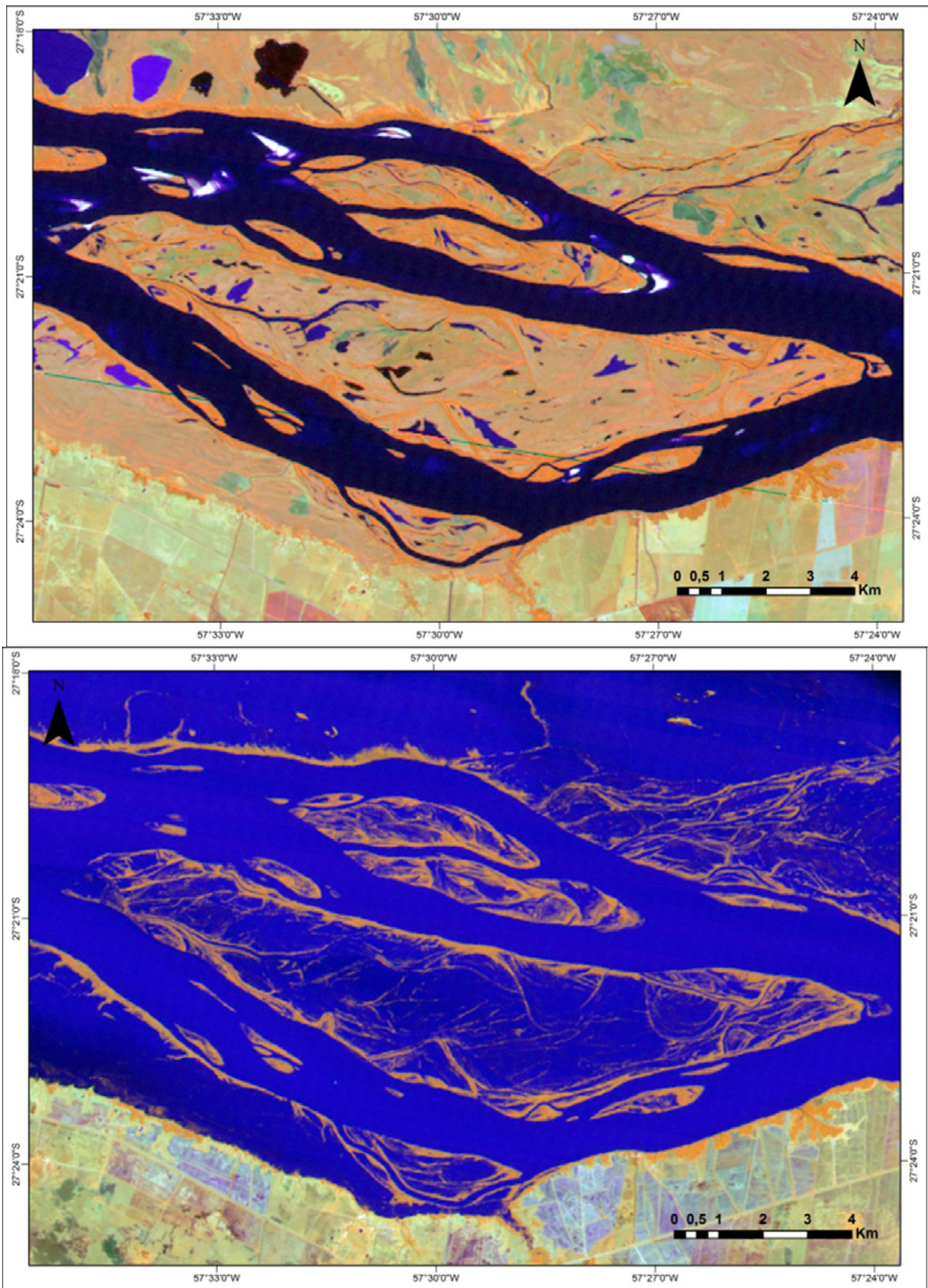

Figura 1: Combinación de bandas 4-5-3 del satélite LANDSAT 5 TM Path/Row 225/079). Años 2008 (Arriba) y 1998 (Abajo).

Publicado en formato digital: Julio César Meza y Prof. Félix Ignacio Contreras. CARACTERÍSTICAS MORFOMÉTRICAS DE LAGUNAS DEL VALLE ALUVIAL DEL RÍO ALTO PARANÁ (TRAMO YACYRETÁCONFLUENCIA). Revista Geográfica Digital. IGUNNE. Facultad de Humanidades. UNNE. Año 13. № 26. Julio - Diciembre 2016. ISSN 1668-5180 Resistencia, Chaco.

En: http://hum.unne.edu.ar/revistas/geoweb/default.htm 
Por tal motivo, son fundamentales los estudios geomorfológicos, ya que condicionan los parámetros fisicoquímicos y biológicos de estos ambientes. Como señala Cabrera et al. (2006) la morfometría de la cubeta de los cuerpos de agua continentales afecta sus características físicas, químicas y biológicas.

De acuerdo con Montoya Moreno (2008), la información morfométrica es necesaria para investigar sobre la erosión, cargas de nutrientes, balances de masa, contenido calórico, estabilidad térmica, comunidades y productividad biológica, entre otras. No obstante, según Vega et al. (2005), la morfometría está relacionada principalmente con el origen, historia y características geológicas de la cubeta y de su cuenca.

Los estudios referidos a las dinámicas de las lagunas de los valles de inundación hacen referencia a las conexiones y pulsaciones hidro-sedimentarias. De allí, que las alturas del nivel del agua y las diferencias topográficas del lugar, pueden generar dinámicas diferentes que a su vez puede verse reflejado en sus formas.

Los conocimientos actuales indican que la heterogeneidad de formas en los cuerpos de agua y la conectividad entre los cauces y las lagunas, preservan la integridad ecológica de los grandes ríos con llanuras aluviales como el Paraná. Por lo tanto, la morfometría y su diversidad, constituyen factores importantes en los estudios ecológicos de estos ambientes lagunares, aportando información para la detección y análisis de los cambios, tanto naturales como antrópicos, a que se hallan sujetos estos sistemas fluviales (Paira, 2003).

En función de lo expuesto, el objetivo de este trabajo es dar a conocer la distribución y morfometría típica de las lagunas del valle aluvial del río Paraná, en su tramo ubicado entre la represa Yacyretá y su confluencia con el río Paraguay.

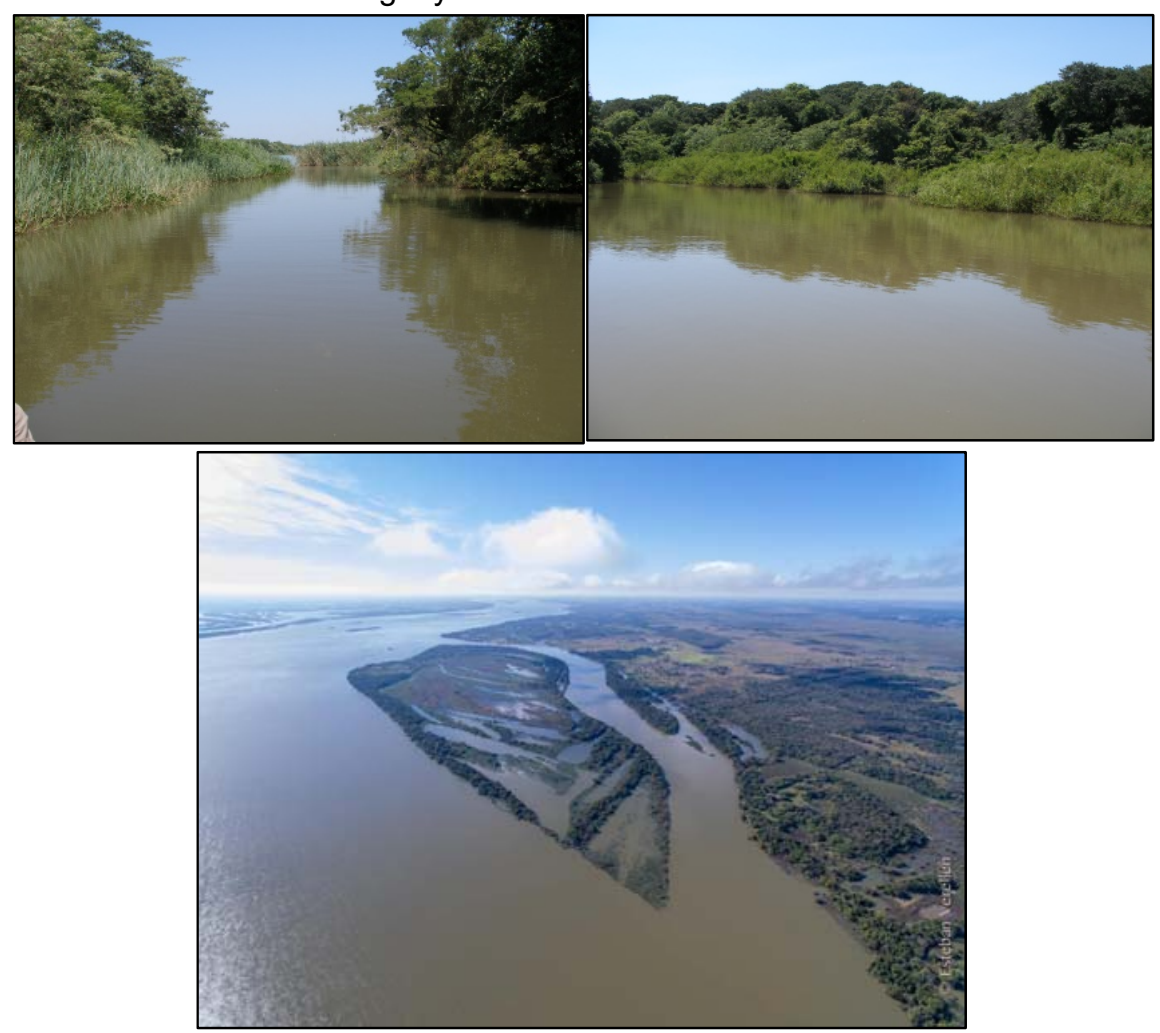

Figura 2: Fotografías de lagunas del valle aluvial del río Alto Paraná (Fotografías: Federico Ruiz Díaz, Esteban Varellen)

Publicado en formato digital: Julio César Meza y Prof. Félix Ignacio Contreras. CARACTERÍSTICAS MORFOMÉTRICAS DE LAGUNAS DEL VALLE ALUVIAL DEL RÍO ALTO PARANÁ (TRAMO YACYRETÁCONFLUENCIA). Revista Geográfica Digital. IGUNNE. Facultad de Humanidades. UNNE. Año 13. № 26. Julio - Diciembre 2016. ISSN 1668-5180 Resistencia, Chaco.

En: http://hum.unne.edu.ar/revistas/geoweb/default.htm 
Revista Geográfica Digital. IGUNNE. Facultad de Humanidades. UNNE. Año 13. № 26. Julio

- Diciembre 2016. ISSN 1668-5180 Resistencia, Chaco

\section{MATERIALES Y MÉTODOS}

Para cumplir con los objetivos de la presente contribución se procedió en primer lugar, a la digitalización manual del área de estudio, corresponde al tramo del río Alto Paraná, entre la represa Yacyretá y la confluencia con el río Paraguay (fig. 3) las islas y lagunas, mediante el software Google Earth, para luego realizar una cartografía temática de dicho área con el empleo de ArcGis 10.1.

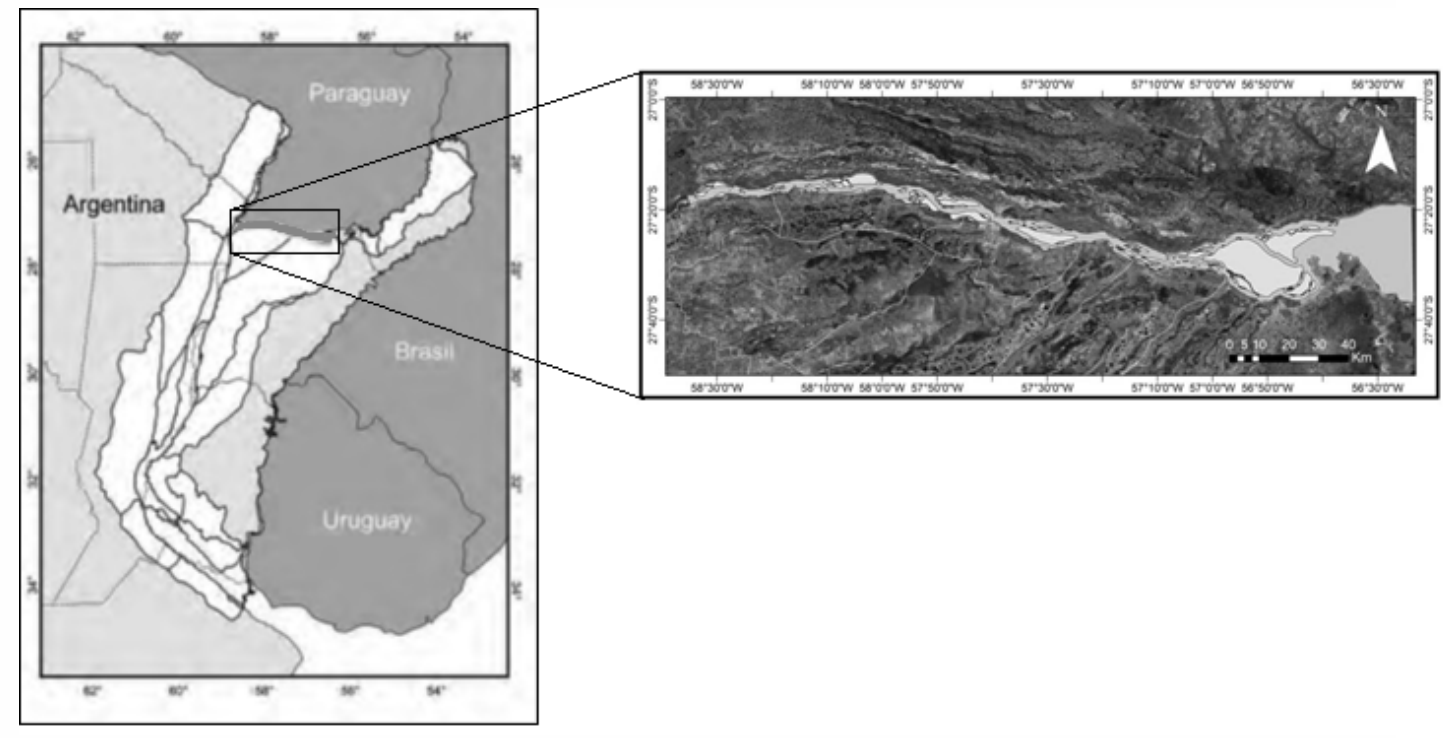

Figura 3: Area de estudio. Fuente: Elaboración propia

Una vez finalizada dicha digitalización, se realizó el cálculo de las siguientes variables morfometricas de la totalidad de lagunas digitalizadas:

Perímetro $(P)$ : Es la línea de intersección de la tierra con el agua.

Superficie $(S)$ o área (A): Extensión del cuerpo.

Desarrollo de la Línea de Costa $\left(D_{\mathrm{L}}\right)$ : Es el cociente entre el perímetro del lago y la superficie que se obtiene a través de la siguiente fórmula, utilizando hoja de Excel.

$$
\begin{gathered}
D_{L}=P / 2 . \sqrt{ }(A . \pi) . \\
P=\text { perímetro }
\end{gathered} \quad A=\text { área }
$$

Con los valores de $D_{L}$ se efectuó una clasificación de formas de la cubeta teniendo en cuenta las formas establecidas por Contreras y Paira (2015).
- $\quad$ Circulares: $1-1,14$
- $\quad$ Subcirculares: $1,15-1,29$
- Triangulares: $1,30-1,99$
- Irregulares simples: $2-2,99$
- Dendríticas: $3-3,99$
- $\quad$ Irregulares complejas: más de 4.

En función de esta clasificación y de los resultados obtenidos se realizaron gráficos a fin de conocer y comparar la predominancia de algún tipo de formas y cantidad según perímetros y áreas.

Publicado en formato digital: Julio César Meza y Prof. Félix Ignacio Contreras. CARACTERÍSTICAS MORFOMÉTRICAS DE LAGUNAS DEL VALLE ALUVIAL DEL RÍO ALTO PARANÁ (TRAMO YACYRETÁCONFLUENCIA). Revista Geográfica Digital. IGUNNE. Facultad de Humanidades. UNNE. Año 13. № 26. Julio - Diciembre 2016. ISSN 1668-5180 Resistencia, Chaco.

En: http://hum.unne.edu.ar/revistas/geoweb/default.htm 
Revista Geográfica Digital. IGUNNE. Facultad de Humanidades. UNNE. Año 13. № 26. Julio

- Diciembre 2016. ISSN 1668-5180 Resistencia, Chaco

\section{RESULTADOS, DISCUSIÓN Y CONCLUSIONES}

Como primer resultado se destaca el mapa de la distribución de 2.574 lagunas correspondiente al área de estudio (principalmente del territorio argentino), resultado de la digitalización. El tramo en cuestión comprende una distancia de $191 \mathrm{~km}$ en línea recta y una superficie estimada de $2.064 \mathrm{~km}^{2}$ (Fig. 4).

Como se indica en la figura 5 , el $90 \%$ de las lagunas posee un perímetro menor a $3 \mathrm{~km}$. El cálculo de superficies demuestra que el promedio es de $66.966 \mathrm{~m}^{2}$, es decir, $66,9 \mathrm{~km}^{2}$, encontrándose 2.182 lagunas ( $85 \%)$ por debajo de ese valor y $392(15 \%)$.

En cuanto al valor de $D_{L}$ la media es de 2,15, existiendo 1607 lagunas que poseen un valor por debajo (68\%) y 967 por encima de ésta (32\%).

En función de estos valores, se puede afirmar que teniendo en cuenta la morfología de las lagunas (Fig.6 y 7), existe un predominio de formas triangulares con valores entre 1,30 y 1,99, también denominadas de "forma de gota" según Paira y Drago (2006; 2007), seguidas de irregulares simples con valores de $D_{L}$ entre 2 y 2,99 , y en menor medida dendríticas, circulares y subcirculares. El valor máximo calculado de este parámetro fue de 12,08 y en este sentido fueron 126 lagunas, solo un $5 \%$ del total, las que superaron el valor de 4 , por lo cual son consideradas como irregulares complejas. En este sentido, resulta lógico afirmar que el desarrollo de línea de costa tiene una relación directa con el perímetro de las lagunas, como ya se ha destacado en Contreras y Paira (2015) y en Contreras et al., (2014).

De acuerdo con Paira y Drago $(2006 ; 2007)$ y teniendo en cuenta que el $86 \%$ de las lagunas analizadas presentan un valor de $D_{L}$ mayor a 2 , podemos señalar que poseen formas alargadas, típicas de valle de inundación. Sin embargo, según éstos mismos autores, tienden a formas circulares a medida que evolucionan hacia una senescencia, pasando por un ambiente de pantano y finalmente a terrestre (proceso de terrestralización o colmatación).

Sin embargo, los altos valores de $D_{\llcorner}$no resultarían atípicos para el área de estudio, ya que valores superiores a 1,5 se encuentran asociados a procesos de inundación y/o anegamientos. En este caso, como se ha podido observar en el figura 1, en crecientes extraordinarias como las observadas en 1998, la totalidad de lagunas quedan cubiertas bajo agua y esta situación, no solo renueva sus aguas, sino que permite recuperar su forma original. De allí el reducido número de formas más simples, principalmente de de formas circulares.

En relación a lo antes dicho, en estos cuerpos de agua se presenta una mayor dificultad de establecer los límites de las lagunas en pótamofases donde el agua abarca la totalidad de la superficie de tierra que las contiene, ya sea una isla o valle aluvial. Incluso en las limnofases pueden presentarse ciertas dificultades a delimitar el área lacustre debido a que si bien el área limnética es claramente identificable, la cubeta puede prolongarse por varios kilómetros y en algunos caso seguir manteniendo una conexión con el río.

Los niveles topográficos del área que las contiene pueden establecer diferencias significativas entre dos o más lagunas que se encuentran muy próximas entre sí. De allí que, y basándonos en los procesos de redondeamiento en los instantes previos a extinguirse, las formas irregulares o con mayor Desarrollo de la Línea de Costa, estarían asociados a lagunas con mayor exposición frente a los pulsos de inundación.

Publicado en formato digital: Julio César Meza y Prof. Félix Ignacio Contreras. CARACTERÍSTICAS MORFOMÉTRICAS DE LAGUNAS DEL VALLE ALUVIAL DEL RÍO ALTO PARANÁ (TRAMO YACYRETÁCONFLUENCIA). Revista Geográfica Digital. IGUNNE. Facultad de Humanidades. UNNE. Año 13. № 26. Julio - Diciembre 2016. ISSN 1668-5180 Resistencia, Chaco.

En: http://hum.unne.edu.ar/revistas/geoweb/default.htm 


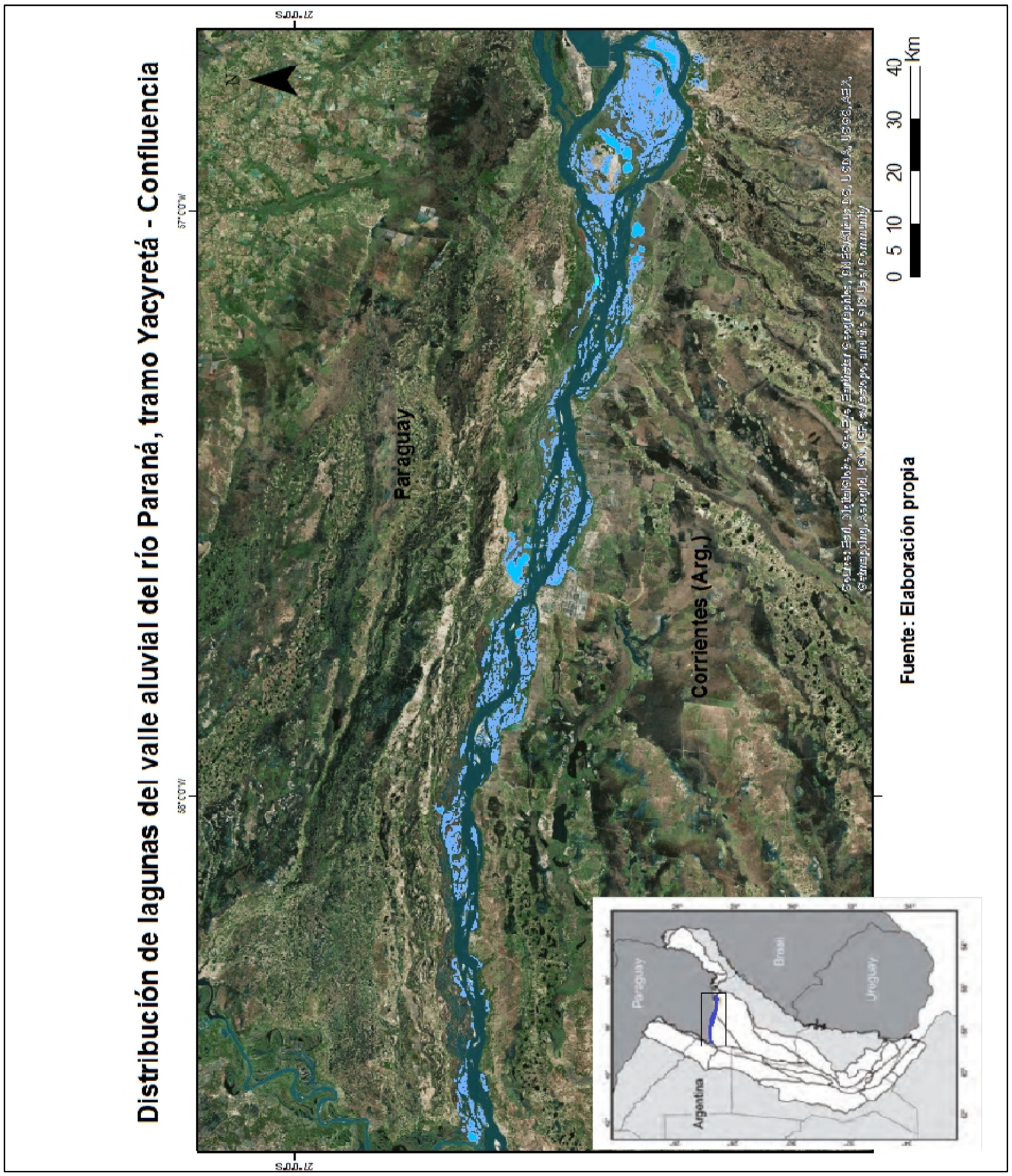

Publicado en formato digital: Julio César Meza y Prof. Félix Ignacio Contreras. CARACTERÍSTICAS MORFOMÉTRICAS DE LAGUNAS DEL VALLE ALUVIAL DEL RÍO ALTO PARANÁ (TRAMO YACYRETÁCONFLUENCIA). Revista Geográfica Digital. IGUNNE. Facultad de Humanidades. UNNE. Año 13. N N 26. Julio - Diciembre 2016. ISSN 1668-5180 Resistencia, Chaco.

En: http://hum.unne.edu.ar/revistas/geoweb/default.htm 
Revista Geográfica Digital. IGUNNE. Facultad de Humanidades. UNNE. Año 13. № 26. Julio - Diciembre 2016. ISSN 1668-5180 Resistencia, Chaco
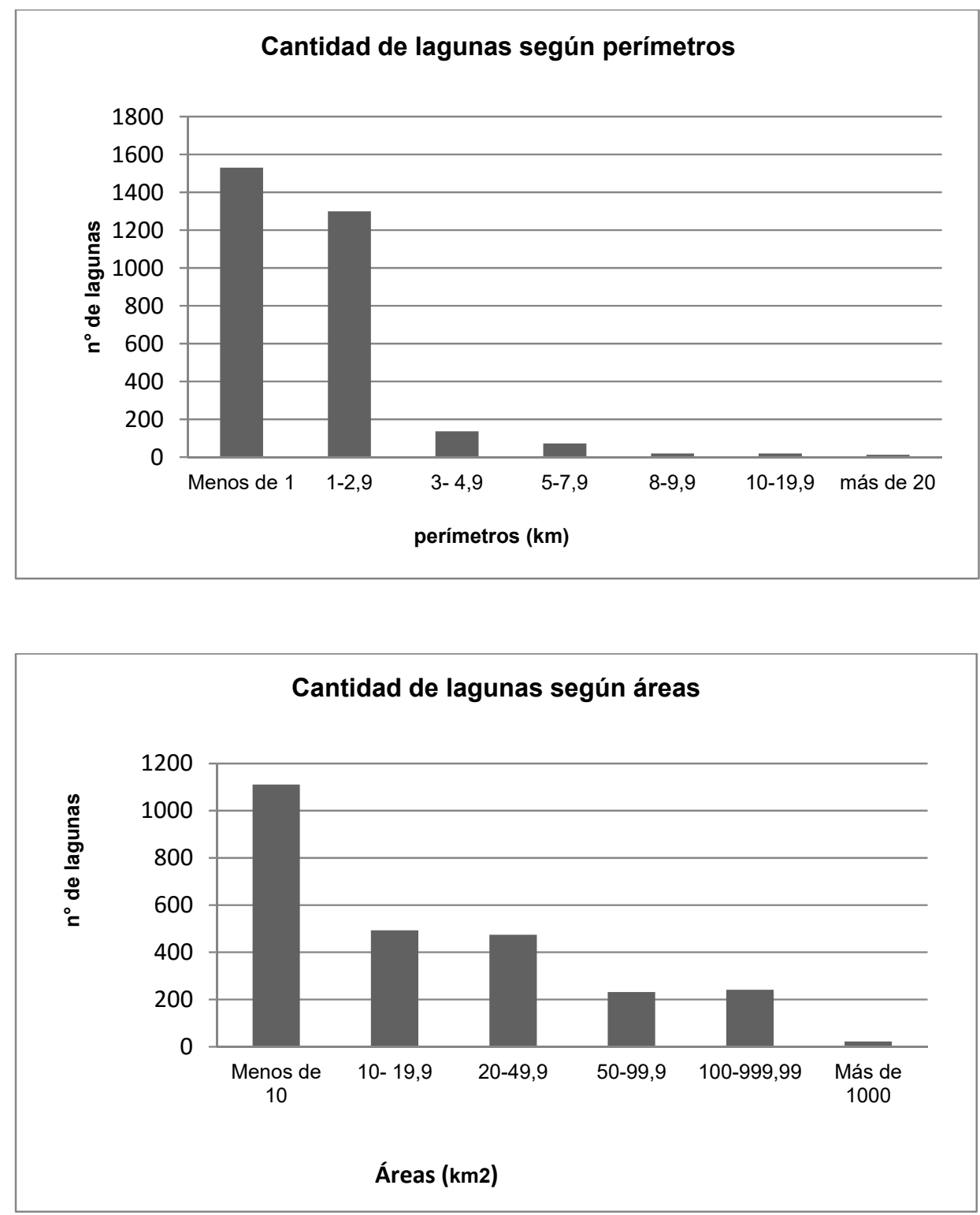

Figura 5: Cuantificación de lagunas según perímetros y áreas. Fuente: Elaboración propia MORFOMÉTRICAS DE LAGUNAS DEL VALLE ALUVIAL DEL RÍO ALTO PARANÁ (TRAMO YACYRETÁCONFLUENCIA). Revista Geográfica Digital. IGUNNE. Facultad de Humanidades. UNNE. Año 13. № 26. Julio - Diciembre 2016. ISSN 1668-5180 Resistencia, Chaco.

En: http://hum.unne.edu.ar/revistas/geoweb/default.htm 
Revista Geográfica Digital. IGUNNE. Facultad de Humanidades. UNNE. Año 13. № 26 . Julio

- Diciembre 2016. ISSN 1668-5180 Resistencia, Chaco

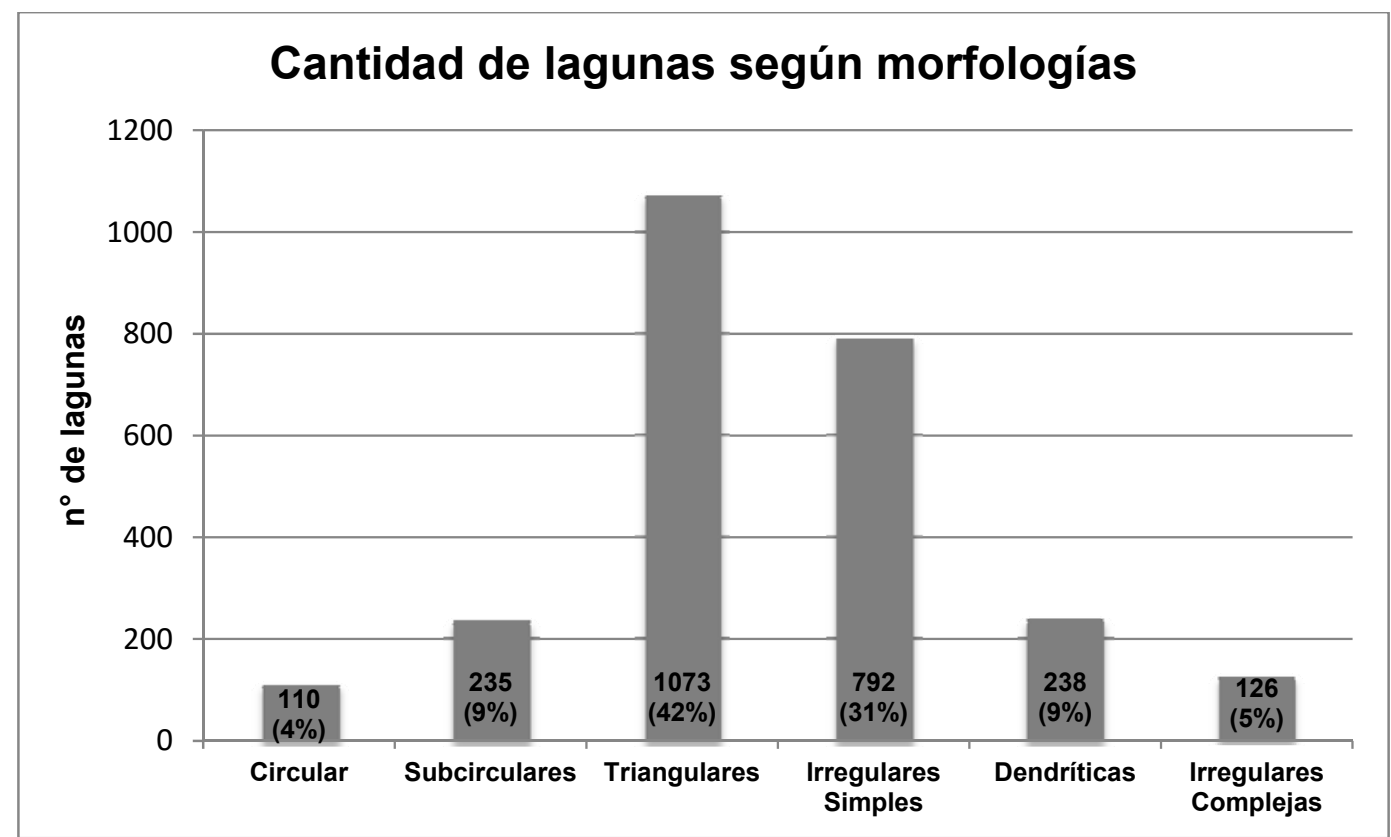

Figura 6: Cuantificación de lagunas según formas establecidas por Contreras y Paira (2015).

Fuente: elaboración propia

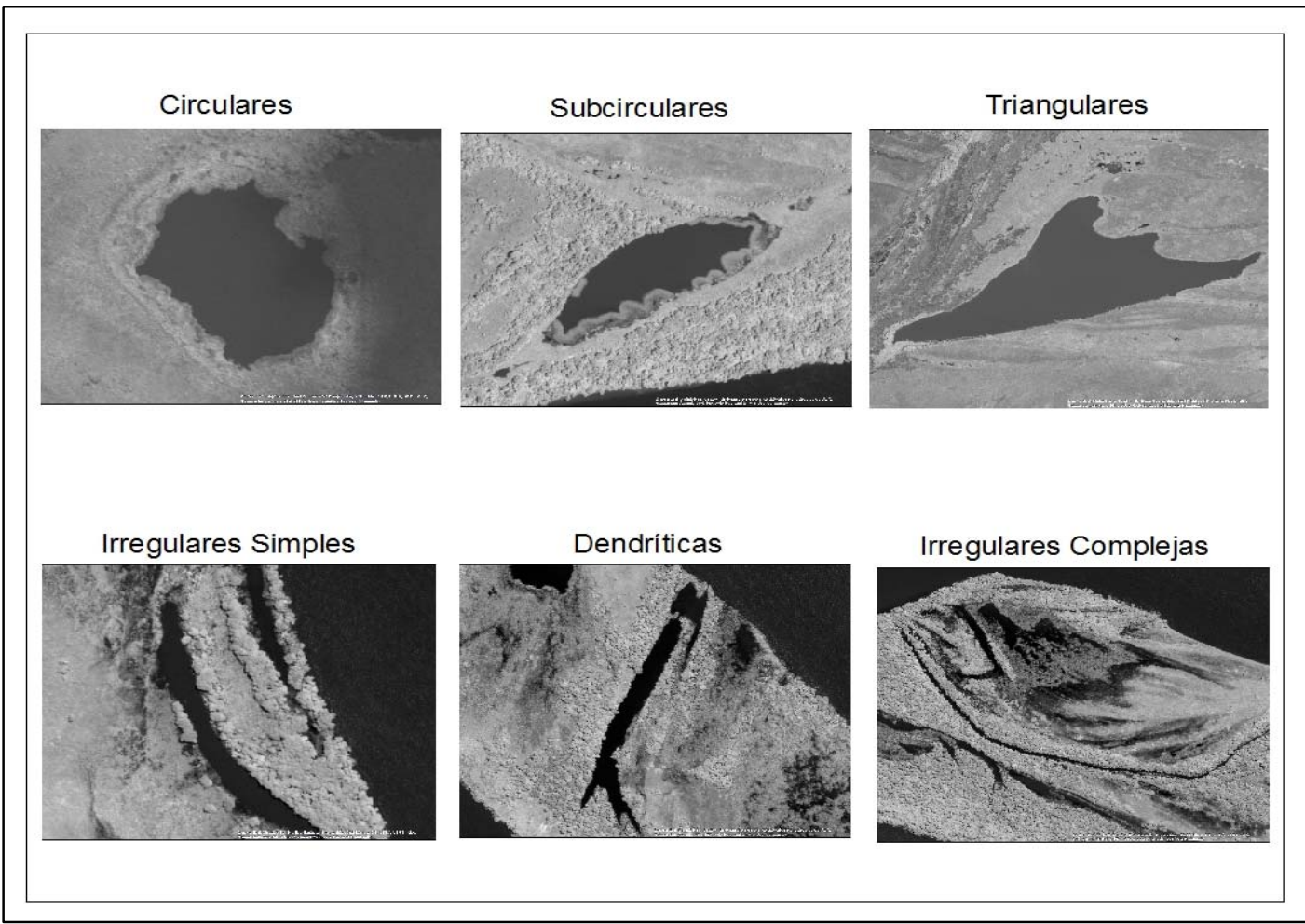

Figura 7: Tipos de lagunas según valores de $D_{\llcorner}$encontradas en el área de estudio.

Fuente: Elaboración propia.

Publicado en formato digital: Julio César Meza y Prof. Félix Ignacio Contreras. CARACTERÍSTICAS MORFOMÉTRICAS DE LAGUNAS DEL VALLE ALUVIAL DEL RÍO ALTO PARANÁ (TRAMO YACYRETÁCONFLUENCIA). Revista Geográfica Digital. IGUNNE. Facultad de Humanidades. UNNE. Año 13. № 26. Julio - Diciembre 2016. ISSN 1668-5180 Resistencia. Chaco. 
En definitiva, el tramo del río Paraná comprendido entre Yacyretá y su confluencia con el río Paraguay presenta un angosto valle aluvial en el que se localizan una gran cantidad de ambientes lénticos asociados a la dinámica hidrosedimentológica del río.

Estos ambientes son de vital importancia para la preservación de la diversidad biológica, considerándose importante realizar un análisis de las variables relacionadas con la geomorfología del área a fin de establecer cuáles son las incidencias de éstas sobre los organismos que allí conviven.

Mediante el cartografiado, con el objeto de detectar patrones de comportamientos, se reconocieron más de 2.500 cuerpos de aguas cuya dinámica depende de los pulsos de inundación del río. En consecuencia, resulta de interés hacer un seguimiento de las formas de estas lagunas, ya que sus cambios morfológicos pueden suceder de un pulso de inundación a otro, particularidad que se acentúan teniendo en cuenta el tipo de conectividad con el cauce principal del río y las diferencias topográficas del sitio en el que se hallen.

\section{Referencias}

(1) La fuente del texto "Sistema Fluvial del río de la Plata" disponible en la página www.RíoParaná.org corresponde al libro "Paraná, el pariente del mar" de Rubén Naranjo et al., (1973) editado por la Biblioteca Popular Constancio C. Vigil, de Rosario,

\section{BIBLIOGRAFÍA}

Cabrera M., Bello C. y Atencio M. 2006. Análisis morfométrico de la laguna Victoria, Parque Nacional Sierra Nevada, Mérida, Venezuela. Acta Científica Venezolana, 57 (3): 93-98.

Casco S. 2003. Distribución de la vegetación fluvial y su relación con el régimen de pulso en el bajo Paraná. INSUGEO, Misceláneas, 12:5 - 12.

Centro estudios sociales y ambientales. 2004. Análisis regional: desastres y ENSO en la cuenca del Paraná. Informe final IAI ENSO-Argentina. Disponible en: http://www.cambioglobal.org/enso/informes/anho4/Argentina/Cap\%203\%20CUENCA\%20DEL\% 20PARANA.pdf

Contreras F. y Paira A. 2015. Comparación morfométrica entre lagunas de la planicie aluvial del río Paraná Medio y la Lomada Norte (Corrientes, Argentina). Cuadernos de Geografía: Revista Colombiana de Geografía. 24 (1): 61-71.

Contreras F., Ojeda, E. y Contreras, S. 2014. Aplicación de la línea de costa en el estudio morfométrico de las lagunas de las lomadas arenosas de Corrientes, Argentina. Contribuciones Científicas G/EA | Vol. 26 | 65-78 p.

Contreras F., Meza J., Scipioni N. y Ruiz Díaz F. (No publicado). Los cambios morfométricos de lagunas aluviales del Alto Paraná a los pulsos de inundación y su incidencia en la diversidad íctica. El caso de Melilla y Galloso.

Junk, W., Bayley, P. y Sparks, R. 1989. The Flood Pulse Concept in River-Floodplain Systems. En Proceedings of the International Large River Symposium (LARS), editado por Douglas P. Dodge, 110-127. Ontario: Honey Harbour.

Montoya Moreno, Y. 2008.Caracterización morfométrica de un sistema fluviolacustre tropical, Antioquia, Colombia. Caldasia 30 (2): 413-420.

Publicado en formato digital: Julio César Meza y Prof. Félix Ignacio Contreras. CARACTERÍSTICAS MORFOMÉTRICAS DE LAGUNAS DEL VALLE ALUVIAL DEL RÍO ALTO PARANÁ (TRAMO YACYRETÁCONFLUENCIA). Revista Geográfica Digital. IGUNNE. Facultad de Humanidades. UNNE. Año 13. № 26. Julio - Diciembre 2016. ISSN 1668-5180 Resistencia, Chaco.

En: http://hum.unne.edu.ar/revistas/geoweb/default.htm 
Revista Geográfica Digital. IGUNNE. Facultad de Humanidades. UNNE. Año 13. № 26. Julio

- Diciembre 2016. ISSN 1668-5180 Resistencia, Chaco

Neiff, J. 1975. Fluctuaciones anuales en la composición fitocenótica y biomasa de la hidrofitia en lagunas isleñas del Paraná Medio. Ecosur 2: 153-183 p.

441.

1990. Ideas para la interpretación ecológica del Paraná. Interciencia 15 (6): 424-

1996. Large rivers of South America: toward the new approach. Verh. Internat.Verein. Limnol. 26 (1):167-181 p.

1999. El régimen de pulsos en ríos y grandes humedales de Sudamérica. En: Tópicos sobre humedales subtropicales y templados de Sudamérica. Ana Inés Malvárez Editora. Universidad de Buenos Aires. 97-146 p.

Paira, A. 2003. Características morfométricas de lagunas de la llanura de inundación del río Paraná Medio. Tesis de licenciatura. FICH, UNL.

Paira, A. y Drago E. 2006. Genetical, Morphological and Evolutional Relationships of the Floodplain Lakes in the Middle Parana River Hydrosystem. Zeitschriftfur Geomorphologie 145:207-228.

2007. Origin, Evolution, and Types of Floodplain Water Bodies. En The Middle $\overline{P a r a n a}$ River Limnology of a Subtropical Wetland, editado Martin H. Iriondo, Juan Cesar Paggi y Maria Julieta Parma, 53- 81. New York: Springer.

Poi A. y Galassi M. 2013. Humedales del río Paraná entre Yacyretá y Confluencia. En Inventario de los humedales de Argentina. Sistemas de paisajes de humedales del corredor fluvial Paraná-Paraguay. Secretaría de Ambiente y Desarrollo de la Nación. Disponible en internet:

http://www.ambiente.gob.ar/archivos/web/Ppnud10/file/publicaciones/2013/inventario humedal es parana paraguay.pdf

Popolizio, E. 2006. El Paraná, un río y su historia geomorfológica. Síntesis de Tesis Doctoral. Revista Geousal N ${ }^{\circ} 3$. Universidad del Salvador.

Popolizio, E. 2001. Los cambios de posición del valle del río Paraná a lo largo de su historia geomorfológica. Comunicaciones Científicas y Tecnológicas, UNNE, T-082 Disponible en: http://www.unne.edu.ar/unnevieja/Web/cyt/cyt/2001/7-Tecnologicas/T-082.pdf

Ríoparaná.org. Sistema Fluvial del río de la Plata. Disponible en: http://www.rioparana.org/index. php?option=com content\&view=article\&id=16:sistema-fluvialdel-rio-de-la-plata\&catid=28:hidrologia\&ltemid=31

Sarafian P. 2006, 2007. Cuenca del río Paraná hasta Confluencia. Disponible en internet: http://www.hidricosargentina.gov.ar/documentos/referencias i8/10.pdf

Serra, P (s/f). Aspectos del modelado fluvial del río Paraná. Disponible en: http://www.icaa.gov.ar/trabajosinves/serra/2.pdf

Valenzuela, M. 2015. El paisaje fluvial del Paraná, convergencias y divergencias entre el paisaje natural y el paisaje cultural. El caso de la ribera de la ciudad de Itatí, Corrientes. En: "Comunicaciones científicas y tecnológicas anuales 2014". Facultad de Arquitectura y Urbanismo, UNNE. p. 133-144.

Vega J., De Hoyos C., Adasorio J., De Miguel J., y Fraile H. 2005. Nuevos datos morfométricos para el Lago de Sanabria. Limnética 24: 115-122.

Publicado en formato digital: Julio César Meza y Prof. Félix Ignacio Contreras. CARACTERÍSTICAS MORFOMÉTRICAS DE LAGUNAS DEL VALLE ALUVIAL DEL RÍO ALTO PARANÁ (TRAMO YACYRETÁCONFLUENCIA). Revista Geográfica Digital. IGUNNE. Facultad de Humanidades. UNNE. Año 13. № 26. Julio - Diciembre 2016. ISSN 1668-5180 Resistencia, Chaco.

En: http://hum.unne.edu.ar/revistas/geoweb/default.htm 